report is devoted to a study of the fauna associated with the sites, and the third to some skulls from the Woodland-culture mound. The value of the report lies in supplementing our information about the distribution of the cultures found, and is enhanced by a map and classified list of archæological sites in Illinois at the beginning. It would have been easier to follow had the descriptions of sites been arranged in some intelligible kind of order, segregating those of various cultures. The introduction says that it was impossible to include the maps and diagrams of the sites; the inclusion of at least some of them would undoubtedly have been an advantage.

3 ?

\section{Mineral-insulated Metal-sheathed Conductors}

IN a recent inpliblisted paper (J. Inst. Elec. Eng., 93, Part 2 J 34, 1946), Messrs. F. W. Tomlinson and H. Whight discuss the development and uses

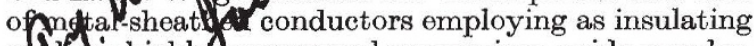
nf phim highly ompressed magnesium oxide powder. In consequende of the high-temperature stability and the good insulating properties of this material, these conductors have found wide application as electrical heating elements in radiant boiler-plates and as power supply cables in circumstances where the avoidance of fire-risk is of special importance, or where the ambient temperature or atmospheric conditions are too severe for other types of electric cable. The low dielectric loss exhibited by magnesium oxide at very high frequencies, combined with the other advantageous characteristics mentioned, has also enabled specially designed cables to be used for certaip important radar purposes.

\section{Status of Translations and Translators}

IN his pam "On Translations", reprinted from

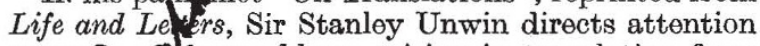
to sop of he problems arising in translation from one Itny age to another, and to inadequacies and inquumies still encountered, although during the pas forty years the quality of translations into Endl sh and the status of translators have steadily improved (London: Allen and Unwin, Ltd. Pp. 8. 6d. net). Sir Stanley emphasizes that first and foremost the translator should be adequately paid, and payment for translation should be a first charge, taking precedence over the author's remuneration. The translator's name should always be given, provided it is his (or her) exclusive work, and it should be a universal practice to print, on the back of the title-page of any translation, the title of the original work. The best remedy for 'mistranslation and for deliberate tampering with the text is informed criticism; bad translations should be denounced. Authors should help by giving preference to publishers who take pride in the quality of their translations and maintain a high standard; but while the publication of translations is in general more speculative than the issue of original work, Sir Stanley does not agree that the publication of translations should be financed by governments. If, however, for commercial reasons any work of outstanding importance had remained untranslated for, say, five years, governments would be well advised to offer to bear the cost of translation, if a publisher was willing in that event to produce the work at his own risk and expense. The pamphlet also includes some notes on "Our Universal Language", which stress the importance of the new demand for British" books.

\section{Museums of To-morrow}

Dr. D. A Allan's presidential address on the occasion of he Muserums Association's annual conference an -Brightgy ths year is reported in full in the Mrsetms. Jownal of August. Under the title, "Avatums- it atis Mutandis", Dr. Allan advocates ro teaching in the muserm and less congestion of ellibits, and he is of the opinion that museums should not strive to increase already immense collections. "To perform its function adequately," he says, "each museum, large or small, must adopt a plan and work it out. It is not enough merely to tidy-up a museum; it must be put into working order; it must show less and teach more." He also appeals for the establishment of special museums to demonstrate the history and applications of British mechanical invention and engineering, mining and agrieulture, and looks for the further development of folk museums so that there may be one to each distinctive region of the British Isles.

\section{Economics of International Trade}

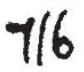

IN Pamphle No. 7, "International Trade", in the "Looking" Erwward" series issued by the Royal Instityte International Affairs, G. A. Duncan point ofit arst that international trade between two contcies really means a multitude of independent tfapetions linked by nothing more serious than the adedent that their participants happen to live in two politically defined areas; hence, while all the problems, spurious as well as real, would still be there if the world "was politically unified, they would not be linked up with political units and political power. He then attempts to set out the nature of the principal questions that arise on the assumption that one State, one supreme political government, embraces the whole earth. The complications introduced by the existence of sixty-odd sovereign and independent States are then considered, and the conditions precedent to the revival and growth of international trade in the post-war world are indicated. International trade, Mr. Duncan argues, consists of an economic substratum overlaid by a political scum. The economic reality is that the real welfare of the world's human population is a function of the optimum use of its diversified resources-mineral, vegetable, animal and: human-under contemporary conditions of technical knowledge.

The optimum pattern, according to Mr. Duncan, is not a matter of merely technical comparison, but of economic balancing, taking into account differing valuations of resources in differing areas, and the correct distribution can only be determined by the empirical method of competition, which continually presents the dilemma of choice between immediate, localized and vocal loss, and more distant, diffused and inarticulate gain. The competitive process can only yield its dividends when it is allowed to proceed so far as possible on economic grounds. The political scum consists of the arbitrary importance attached to trade crossing political frontiers and to the significance of partial calculations about its component elements; the tendency to think of international trade as trade between definable political entities instead of an arithmetical accident; and the invasion of economic problems by notions of political power and prestige. The problem for economic statesmanship in the next fow years, he concludes, is that of working out by common agreement a form and extent of political impositions upon international 
trade that will inhibit its growth as little as possible, while satisfying all reasonable political desires. 6 :

\section{Bibliography of Seismology}

THrs valuable biblifgraphy is being continued by Dr. Ernest An F a lgson; Pub. Dominion Observ., Ottawa, 13, N. 16, 17 and 18, comprise items 5788-6048. Nhe bibliography is concerned with publicatins in pure and applied seismology and oth subjects having a direct bearing on seismologida problems. It is pleasing to see notes of Russian work, much of which was done during the War. One such is by E. E. Petrenko, "A Net of Co-ordinates for Determining the Epicentre of an Earthquake" (Akademiia Nauk, U.S.S.R., Trudy Seismolog. Inst., No. 106, 12-16, Moscow, 1941). This is in Russian, but it has been translated by W. Ayvazoglow and V. Skitsky for Geophysical Abstracts. Greek work is largely centred on the collected papers of Prof. N. A. Critikos, published by his colleagues on the occasion of the thirty-fifth anniversary of his scientific work (Item 5901). An especially important piece of American work is listed as Item 5956, by D. S. Carder, "Seismic Investigations in the Boulder Dam Area 1940-41, and the Influence of Reservoir Loading on Local Earthquake Activity" (Bull Seis. Soc. Amer., 35, No. 4, 175-192, Oct. 1945). This work has been particularly successful in locating epicentres of small shocks and associating them with fault planes. It may easily have far-reaching results on reservoir engineering. Considerable useful work has been done in New Zealand; for example, Item 5980, by W. M. Jones, refers to three papers, including "Determination of Epicentres in the South Pacific from Differences in the Arrival Times of SeS" (N:Z. J. Sci. and Tech., 26 , No. $6 \mathrm{~B}, 366-369)$. This paper shows that there is less ambiguity in epicentral determination using $S c S$ pulses than when using $P$ pulses in certain cases owing to less variation caused by the depth of focus. British work is mentioned, including Item 5862, Prof. H. -H. Plaskett's tribute to the seismological work of Miss E. F. Bellamy; Item 5880, Sir George Simpson's tribute to the work of the late Dr. F. J. W. Whipple; and Item 5930, by Dr. R. Stoneley, "Earthquakes" (Observ., 66, No. 824). There is also a list of references published in Nature.

\section{University of London: Appointments}

THE following appointments have been made: Dr. C. A. Hart, to the University chair of surveying and photogammetry tenable at University College as from gctober 1; in 1927 he became assistant lecturer/n the Department of Municipal Engineering and $H$ giene at University College, and during 194246 bo was officer in charge of research, Directorate of Mifitary Survey, War Office: Dr. C. V. Harrison, to the University readership in morbid anatomy tenable at the British Postgraduate Medical School as from October 1, 1946 ; Dr. Harrison was formerly lecturer in pathology in the University of Liverpool, and since 1944 has been chief pathologist to the Ministry of Supply and chief consultant in pathology to the Admiralty.

The following doctorates have been conferred: D.Sc. : Mr. W. E. Duncanson, recognized teacher of University College; D.Sc.(Eng.) : Dr. Harold Heywood, Imperial College of Science and Technology; D.Sc.(Econ.) : Mr. K. H. L. Key, Institute of Education.

\section{Re-opening of the British Museum (Natural History) \\ Those poptions of the British Museum (Natural} History) that have been restored have been re-opened to the pyrlic. The hours of opening are 10 a.m.-6 p.m. on wo kdays, and 2.30 p.m.-6 p.m. on Sundays. The Museum suffered considerably from bomb-blast and fires resulting from air raids during the War. Zittle or no irreplaceable material was lost, as all the most valuable specimens had been evacuated to places of safety. But the Botanical and Shell Galleries were destroyed (the latter fortunately being empty at the time), and in many of the galleries exhibits were damaged, notably those of birds and mammals in the Western Wing. The Museum has been re-opened as soon as the minimum of essential repairs could be completed, but as yet the public can be admitted to only a few of the galleries on the ground floor, namely, the Central and North Halls, the Fish Gallery, the Insect Gallery, the Reptile Gallery and the Whale Hall. Selections of specimens from the more seriously damaged parts of the exhibition are on view temporarily in these galleries. As the work of repair and reconstruction proceeds, more galleries will become available for exhibition purposes and will be reopened.

\section{Announcements}

Prof. C. Lander, who has just retired from the chair of mechanical engineering at the City and Guilds College, University of London (see Nature, Augast 10, p. 191), has been appointed dean of the Military College of Science.

DR. JACOB 1 AKKER, of the Netherlands State Coalmines, has joined the National Coal Board in Great Britain as adviser to the chief mining engineer. $\mathrm{He}$ is widely recognized throughout the coal-fields of Europe as a leading expert on 'horizon mining', that is, driving main roadways straight out from the pitbottom and working the coal wherever it is struck.

Dr. Frank BeLL, principal of Lancaster Technical College since 1941, has been appointed professor of chemiory at the Belfast College of Technology in suceossion to Dr. Henry Wren. Dr. Bell has held previous appointments at the Wellcome Chemical Research Laboratories, Blackburn Technical College and Battersea Polytechnic.

A David Anderson-Berry Silver-Gilt Medal, together with a sye of money amounting to about $£ 100$, will be ayyrded during 1947 by the Royal Society of Edjoburgh to the person who, in the opinion of the Gruncil, has recently produced the best work on the therapeutical effect of X-rays on human diseases. Applications for this prize are invited. They may be based on both published and unpublished work and should be accompanied by copies of the relevant papers. Applications must be in the hands of the General Secretary, Royal Society of Edinburgh, 22 George Street, Edinburgh 2, not later than January 31,1947 . It should be noted that an extension of the period allowed for the receipt of papers has been made.

Erratum The "wonderful one-hoss shay" rereferred to in Nature of October 19, p. 537, was wrongly attributed to Longfellow; the phrase comes from Oliver Wendell Holmes' “The Deacon's Masterpiece". 